\title{
El Sistema Privado de Pensiones como obstáculo para la construcción de la Seguridad Social en los países subdesarrollados: Lecciones desde el caso peruano
}

\author{
The Private Pension System as an obstacle to the construction of Social Security in underdeveloped countries: Lessons \\ from the Peruvian case \\ LUIS ALBERTO QUINTANA GARCÍA ${ }^{1}$ \\ Universidad Nacional Mayor de San Marcos, Perú
}

\section{Resumen:}

En el presente trabajo se analiza el desarrollo del Sistema Privado de Pensiones, desde la experiencia peruana, respecto a tres ámbitos fundamentales: 1) Su proceso de implementación y consolidación, 2) el papel de la inversión de los fondos de pensiones en el ámbito tanto exterior como doméstico, y 3) los conflictos estructurales durante la pandemia, específicamente aquellas vinculadas a las medidas de retiros de fondos de pensiones y sus efectos; a partir de ello, evaluaremos críticamente el papel del Sistema Privado de Pensiones ante la posibilidad de construir una Seguridad Social genuina. Con ello, se establecen los lineamientos generales para que países en las mismas condiciones de subdesarrollo y dependencia puedan evaluar el panorama futuro de las reformas previsionales que deberán incidir, necesariamente, sobre la estructura económica.

Palabras clave: Sistema Privado de Pensiones, Economía Nacional, Estado, Seguridad Social, Administradoras Privadas de Fondos de Pensiones.

\begin{abstract}
:
This paper analyzes the development of the Private Pension System, from the Peruvian experience, with respect to three fundamental areas: 1) Its implementation and consolidation process, 2) the role of investment of pension funds in the field both foreign as well as domestic, and 3) structural conflicts during the pandemic, specifically those related to pension fund withdrawal measures and their effects; Based on this, we will critically evaluate the role of the Private Pension System before the possibility of building a genuine Social Security. With this, the general guidelines are established so that
\end{abstract}

\footnotetext{
${ }^{1}$ Abogado por la Universidad Nacional Mayor de San Marcos (UNMSM). Candidato a Magíster por la UNMSM. Con estudios de perfeccionamiento en relaciones laborales y protección social por la Universidad Alcalá (UAH) y Economía por la Universidad Complutense de Madrid (UCM). Miembro del Grupo de Investigación Laboralistas y del Taller de investigación en Derecho Laboral y de la Seguridad Social.
} 
countries in the same conditions of underdevelopment and dependency can evaluate the future outlook of pension reforms that must necessarily affect the economic structure.

Keywords: Private Pension System, national economy, State, Social Security, Private Pension Fund Administrators.

\section{Introducción}

A partir de 1992, en el Perú se inició un proceso de reestructuración del Estado y del sistema económico, cuya repercusión alcanzó a la seguridad social, conllevando a un conjunto de medidas de ajustes económicos impulsados por los órganos financieros internacionales (v.g. cartas de intención entre el Fondo Monetario Internacional y Perú), mediante los cuales, se fomentó un tipo de seguridad social: Las Administradoras Privadas de Fondos de Pensiones (AFP).

A casi 27 años de la existencia del SPP, resulta importante analizar el proceso histórico que permitió su creación, expansión y consolidación a fin de comprender el cumplimiento de los objetivos formales por el que se fundaron: Otorgar pensiones adecuadas, oportunas, suficientes y completas; este proceso debe señalarnos el papel del Estado y el futuro de las AFP.

Además de ello, resulta central avocarnos sobre el problema de las inversiones de los fondos de pensiones (tanto a escala nacional e internacional), esto, debido a que, representa el eje neurálgico que determina el funcionamiento, diseño y estructura del SPP. Esto resulta fundamental, porque nos permite comprender la naturaleza, hegemonía y tipos de capitales en los que se invierte los fondos de pensiones, así como la ligazón que tiene con el desarrollo económico de un país determinado, y, en consecuencia, con la posibilidad de construir una seguridad social.

Entre los diversos conflictos estructurales del SPP, resulta fundamental analizar aquel agudizado por la pandemia: Los retiros de los fondos de pensiones, conflicto que debe ser analizado desde una visión integral proporcionada por el Derecho de la Seguridad Social, pues, si bien es cierto, las coyunturas pueden exponer problemas específicos, estos, muchas veces, son síntomas o expresiones de un problema de la estructura económica de un país determinado. Con dicho planteamiento, se podrá brindar herramientas de análisis a los sectores sobre los cuales recaen las decisiones previsionales del SPP: Los afiliados, para que puedan adoptar medidas orientadas a cambiar su situación y los factores estructurales que la determinan.

Por lo expuesto, consideramos que, la experiencia del desarrollo del SPP de nuestro país, permitirá que países en las mismas condiciones de subdesarrollo y dependencia, puedan comprender la real naturaleza del SPP, avizorar el futuro sobre la necesidad de transformarla y orientar la discusión sobre la construcción de una seguridad social genuina vinculada a proyectos de transformaciones estructurales. 


\section{Proceso de implantación del SPP en el Perú}

\subsection{Antecedentes y naturaleza de las reformas previsionales}

La implementación de las políticas económicas de los organismos internacionales, principalmente, del Banco Mundial (BM) y el Fondo Monetario Internacional (FMI), establecidas a través del Consenso de Washington (cuya formulación se debe al economista británico John Williamson, que en 1989, lo plasmó en su trabajo intitulado: What Washington means by policy reform), se iniciaron a partir de 1990 en los países subdesarrollados, trazando las líneas directrices de ajuste y disciplinamiento que debieron implementar los países latinoamericanos en crisis económica, con el objetivo de sentar las bases para un tipo particular de reestructuración funcional al diseño político de dichos organismos financieros.

En ese sentido, este consenso tenía como base fundamental la "liberalización” de la economía, que supuso la expulsión de un tipo de Estado intervencionista que en el S. XX cumplió un rol director y determinante en el proceso económico nacional, sin embargo, para este periodo, dicho tipo de Estado ya no resultaba consustancial a los intereses económicos del imperialismo, por lo que se redujo su participación a la mínima expresión (subsidiariedad), entregando los sectores económicos estratégicos a los grandes capitales extranjeros, principalmente, aquellos sectores productivos que el Estado intervencionista abandonó, cedió o vendió (a precios irrisorios), para volver así, históricamente, al laissez faire, laissez passer, con el objetivo de atizar las relaciones económicas de un capitalismo que no sienta las bases para la industrialización del país, sino que, por el contrario, reproduce la manufactura, los servicios y la extracción de petróleo, gas y minerales, como país de la periferia.

A ello se añade que, el movimiento sindical y popular, durante esta etapa, entra en crisis, ya que, dichos sectores entran en una fase de crisis, tanto que, el Capital y el Estado, plantearon mecanismos explícitos de eliminación de derechos conquistados y promovió, abiertamente, una regresión de los derechos sociales y laborales, cuya justificación estarían dadas por la crisis económica. Aquí debemos resaltar que, la ideología “neoliberal” promovida, consistió, básicamente, al regreso de los postulados de mínima intervención del Estado y que los sectores privados administren, dirijan y promuevan las políticas económicas de un país, incluso si esto les lleva a utilizar al Estado como palanca para sus objetivos, a través de la omisión Estatal de las obligaciones mínimas que los convenios internacionales establecen en materia de derechos sociales.

En el Perú, esta situación repercutió en el fomento de la creación del Sistema Privado de Pensiones (SPP), donde los organismos internaciones tuvieron un papel predominante:

El interés y la injerencia de los organismos multilaterales [BM y el FMI] por el sistema de pensiones peruano se remontan al año de 1978, cuando el gobierno peruano restableció relaciones con el FMI. Y el ministro Javier Silva Ruete y el presidente del Banco Central, Manuel Moreyra, firmaron una carta de intención, que tuvo como subproducto la publicación, pocas semanas después, del Programa económico de 1978-1980, en el cual se hizo un detallado listado de objetivos de política y las acciones a seguir durante el periodo indicado. En este texto, el gobierno señalaba su interés no solo en privatizar «aquellas empresas que por su naturaleza no es conveniente que tengan participación estatal» sino también en «racionalizar la administración del Seguro Social y establecer un sistema eficiente de cálculos actuariales con miras a introducir los ajustes correspondientes» (Rojas, 2014: 79-80). 
Agrega también que, esta práctica se desarrolló en lo sucesivo, constante e ininterrumpidamente, pues

“(...) prácticamente en todas las cartas de intención firmadas por el gobierno peruano entre 1991 y 2007 se hace referencia a la reforma del sistema de pensiones, lo cual pone en evidencia no solo la importancia que daba el FMI a esta cuestión, sino también la gran disposición del gobierno peruano de atender tales demandas” (Rojas, 2014: 80).

Con ello, se evidencia que, dentro del marco de las "reformas" propiciadas y fomentadas por los órganos internacionales, estas sirvieron, principalmente, para eliminar todas las formas organizativas de los trabajadores y fomentar un tipo de Estado funcional a la rentabilidad del capital extranjero a través de sus directivas económicas, de esta forma, la ayuda económica para salir de la crisis, era una premisa ilusoria, pues, lo real consistió en la necesidad económica de nuevos mercados para garantizarse medios de incremento y rentabilidad económica a sus capitales, a través del disciplinamiento impuesto en las recetas económicas contra los países subdesarrollados, lo que reestructuró y atizó las relaciones de dominio y dependencia al capital extranjero.

\title{
2.2. Implementación y consolidación
}

Con la promulgación del Decreto Ley 25897 (6/12/1992), se crea el SPP, inspirado en la experiencia chilena y cristalizando los ideales capitalistas de administrar las ingentes cantidades dinerarias provenientes de las remuneraciones de la clase trabajadora (asalariado o no), se implementa un tipo de seguridad social fomentado por los órganos internacionales en los países del Tercer Mundo: Las Administradoras Privadas de Fondos de Pensiones (AFP), sin embargo, este proceso, en sus inicios, obtuvo resistencia de los sectores del movimiento sindical, conforme a lo siguiente:

\begin{abstract}
Inicialmente, el Sistema Privado de Pensiones en el Perú fue objeto del D. Leg. 724, del 10/11/1991, pero no pudo ser puesto en vigencia el 28/07/1992, como se había previsto, por las vacilaciones sobre su viabilidad del Gobierno de entonces. Luego del Golpe de Estado del 5 de abril de 1992, el Gobierno de facto publicó el anteproyecto de un decreto ley que debía sustituirlo. El debate suscitado a raíz de esta publicación permitió advertir la inconveniencia de ese régimen para los trabajadores, quienes, según la Constitución de 1979, debían ser asegurados obligatorios del Instituto Peruano de Seguridad Social (IPSS), y mostró, además, el desequilibrio financiero que produciría en el IPSS. La ola de críticas al anteproyecto decidió al Gobierno a anunciar la publicación de un nuevo proyecto de decreto de Ley de fondos privados de pensiones. Pero no lo hizo y, antes bien, expidió directamente el D. Ley 25897, ejecutando su compromiso con los grupos capitalistas que lo apoyaban (Rendón, 2008: 461).
\end{abstract}

Al iniciarse la aplicación del Decreto Ley 25897, en junio de 1993, concurrieron ocho AFP, quienes desenvolvieron una gran publicidad para afiliar a los pensionistas del SNP, generándose así, una disputa con el SNP, donde el Estado colaboró, explícitamente, en el traslado de los afiliados del SNP hacia al SPP (v.g. mediante bonos de reconocimiento) y en la modificación sustantiva de la regulación que sobre la tasa de aportación, reglas de jubilación y de afiliación, entre otros, que fueron favoreciendo, directa o indirectamente, al SPP en detrimento del SNP (o lo que quedaba de él).

Es por ello que, la existencia del SPP estaba condicionada al deterioro y desmantelamiento del SNP, por lo que no pudo haber coexistencia pacífica ni mucho menos complementariedad, pues, el SPP surgió a costa del SNP, por ello, siguiendo a Montoro (1999), debemos señalar tres consecuencia de la implementación del SPP sobre el SNP: 1) En relación a los aportantes, en el SNP la proporción de trabajadores activos por trabajador pasivo disminuyó de 18 en 1980 a 7 en 1992, y posteriormente, a 4 en 1996, debido al pase de aportantes del SNP al SPP, lo que agudizó, a partir de 1995, el 
déficit del SNP entre las contribuciones y el pago de pensiones, obligando al Estado a transferir recursos del Tesoro Público para cubrirlos, asimismo, la tasa de aporte pasó a estar totalmente a cargo del trabajador de $11 \%$ en 1995 a 13\% a 1997 de su remuneración asegurable; 2) en relación a la cobertura, la población nacional en edad de aportar pasó de $25 \%$ en 1980 a $12 \%$ en 1995, mientras que la cobertura aumentó de $16 \%$ a $29 \%$ en los mismos años, ello debido al despliegue de las operaciones de las AFP para captar trabajadores, 3) en relación a los sueldos reales, el salario implícito promedio real de la base de aportaciones valorizados en nuevos soles constantes de 1996, pasó de S/.1300 (USD 347) en 1980 a S/. 400 (USD 106) en 1992, esto ocasionó que las contribuciones totales del SNP disminuya en 57\% en términos reales entre 1980 y 1992.

Para 1993, se advertía claramente que este “nuevo” SPP, tendría graves deficiencias consustanciales a la naturaleza de su configuración, que lo acompañarán como sello distintivo desde su creación, y estos son:1) No pertenece a la seguridad social, sino es un régimen de acopio de los recursos monetarios de los trabajadores con la finalidad de invertirlos en la adquisición de títulos, teniendo como base la edad para acceder a la pensión, 2) No garantiza una pensión mínima, tampoco la permanencia ni acrecimiento del valor real de las pensiones invertidas (inclusive en épocas de crisis económicas, inflación, entre otros), cuyas implicancias afectan el monto y la duración de las pensiones a recibir por los asegurados, 3) Los trabajadores afiliados no intervienen en las operaciones de los fondos de pensiones, no tienen representantes en las AFP ni pueden oponerse a las operaciones de ninguna forma(v.g. cuando la no inversión de las AFP implica que desaparezca la parte invertida de su pensión), 4) Privilegio de la adquisición, por las AFP, de bonos del Estado a fin de aliviar los déficit o para contribuir a saldar las «obligaciones» internacionales (v.g. pago de la deuda externa), lo que se opone a la búsqueda de mejorar la situación pensionaria de los asegurados (Rendón, 1993).

En este contexto, el Estado peruano, no pudo perder su carácter de clase, a través de la cual, contribuyó a desmantelar los sectores, que en otrora, habían sido intervenidos y dirigidos por una facción de la burguesía, y que en el periodo de reestructuración, generó la necesidad- para las clases dominantes- de virar hacia el apoyo a la burguesía rentista, cuya implementación de políticas neoliberales estuvo en consonancia con las políticas de ajuste y disciplinamiento de los órganos internacionales (v.g. FMI, BM), y que en el caso de la seguridad social, buscó absorber las cuotas de plusvalía que representaban los fondos del "nuevo" SPP a través del sector financiero.

En ese sentido, el objetivo de capitalizar un porcentaje de las remuneraciones de los trabajadores a través de la AFP, no puede comprenderse como propuesta complementaria a la seguridad social ineficiente del Estado, ni mucho menos, como forma alternativa frente a las pensiones irrisorias otorgadas por el SNP, por el contrario, "una manera, [...], de entender el interés de la banca privada por la creación del SPP reside en la posibilidad de que los grupos financieros apuntasen a incorporar [a las] AFP como fuentes adicionales de financiamiento para sus empresas no financieras”(Rojas, 2014: 83), así, este sector se proyecta a reproducir sus formas económicas propias: Manufactura, servicios y comodities, cuya reproducción mantiene intacto las relaciones de subordinación al capital financiero internacional, sin la mayor proyección de desarrollar las fuerzas productivas nacionales que industrialicen nuestro país.

Para inicios del 2021, el proceso de concentración y centralización ha generado que de ocho AFP instaladas al inicio, sólo sean en la actualidad cuatro AFP los dueños del 
mercando previsional, proceso mediante el cual, las AFP han pasado por diversas fusiones y adquisiciones, teniendo las siguientes características:

1) AFP Habitat tiene como accionista mayoritario Habitat Andina S.A. (99.98\% de participación), la que a su vez tiene como accionista mayoritario a la Administradora de Fondos de Pensiones Habitat S.A (AFP Habitat Chile) con un 99,9\%, cuya entidad controladora es la Administradora de Inversiones Previsionales SpA, la que a su vez, el 50\% de sus acciones son de propiedad de la Construcción S.A. (ILC), cuyo controlador final es la Cámara Chilena de la Construcción A.G. con un 67\%; el 50\% restante de acciones son de propiedad de Prudential Chile SpA, la que a su vez es de propiedad en un $100 \%$ de Prudential Chile SpA II cuyo controlador final es Prudential Financial Inc. (conjuntamente Prudential). Entre ILC y Prudential, mantienen los mismos derechos políticos y económicos y existe pactos de accionistas que prevean, entre otras materias, mecanismos de primera opción de compra de acciones de AFP Habitat de Chile (AFP Habitat, 2021: 19; AFP Habitat, 2020: 29-30).

2) Profuturo AFP forma parte del grupo económico The Bank of Nova Scotia (BNS) Scotia, Banco internacional con sede en Toronto, Canadá, que participa indirectamente a través de Perú Holdings S.A, con el 99,9974\% de acciones (Profuturo AFP, 2020: 16-17).

3) Prima AFP, cuyo accionariado está controlado por el Grupo Crédito S.A. (Credicorp) con el 99.99\% de acciones, grupo financiero peruano, donde destaca el Grupo Romero (Prima AFP, 2020: 12- 15).

4) AFP Integra, se encuentra representada por dos grupos: El primero es SURA Asset Management Perú S.A. con el 55.82\%, cuyo capital está invertido en Perú; el segundo, SURA Asset Management S.A., cuyos capitales residen en Colombia y tiene una participación del 44.18\%, esta AFP forma parte del grupo económico «Grupo Empresarial SURA», el cual es un grupo multilatino listado en la Bolsa de Valores de Colombia (AFP Integra, 2021: 6).

Todas estas empresas se encuentran vinculados a los sectores financieros, quienes, desde el punto de vista económico, direccionan la política económica Estatal para garantizar la viabilidad de sus inversiones en el tiempo, pero además, como lo indica Oré (2007), el SPP se encuentra controlado por la oligarquía financiera donde coexisten capitales nacionales y extranjeros en actividades especulativas, teniendo como mecanismo principal de rentabilidad los títulos de deuda pública emitidos por el Estado peruano, garantizándose la existencia de un mercado cautivo de afiliados, cuyos aportes son la única fuente de ingresos productivo, y un grupo político a su servicio.

Así, los fondos de pensiones se invierten en actividades improductivas y especulativas en el exterior, ausentes de objetivos nacionales y desarticulados del desarrollo económico nacional, por el contrario, lo que ha generado este tipo de inversión es la consolidación de grupos de poder económico que controlan y direccionan el destino de los fondos de pensiones. 


\section{Inversión de los fondos de pensiones}

\subsection{Comportamiento del capital extranjero}

Al diciembre del 2020, las AFP cuentan con un total de 7’780,721 afiliados, asimismo, la totalidad del dinero de dichos afiliados que administra las AFP asciende a S/ 164,875 millones (USD 44,053 millones), lo cual representa el 23,57\% del PIB del Perú.

La forma en que se inviertan dichos fondos de pensiones nos pueden ofrecen un claro panorama de la caracterización de nuestra estructura económica, así, una evaluación histórica de los sectores económicos donde se invierten los fondos de pensiones nos indicará el comportamiento de los capitales existentes y evaluar el capital predominante.

Para analizar ello, a continuación, tenemos el siguiente cuadro:

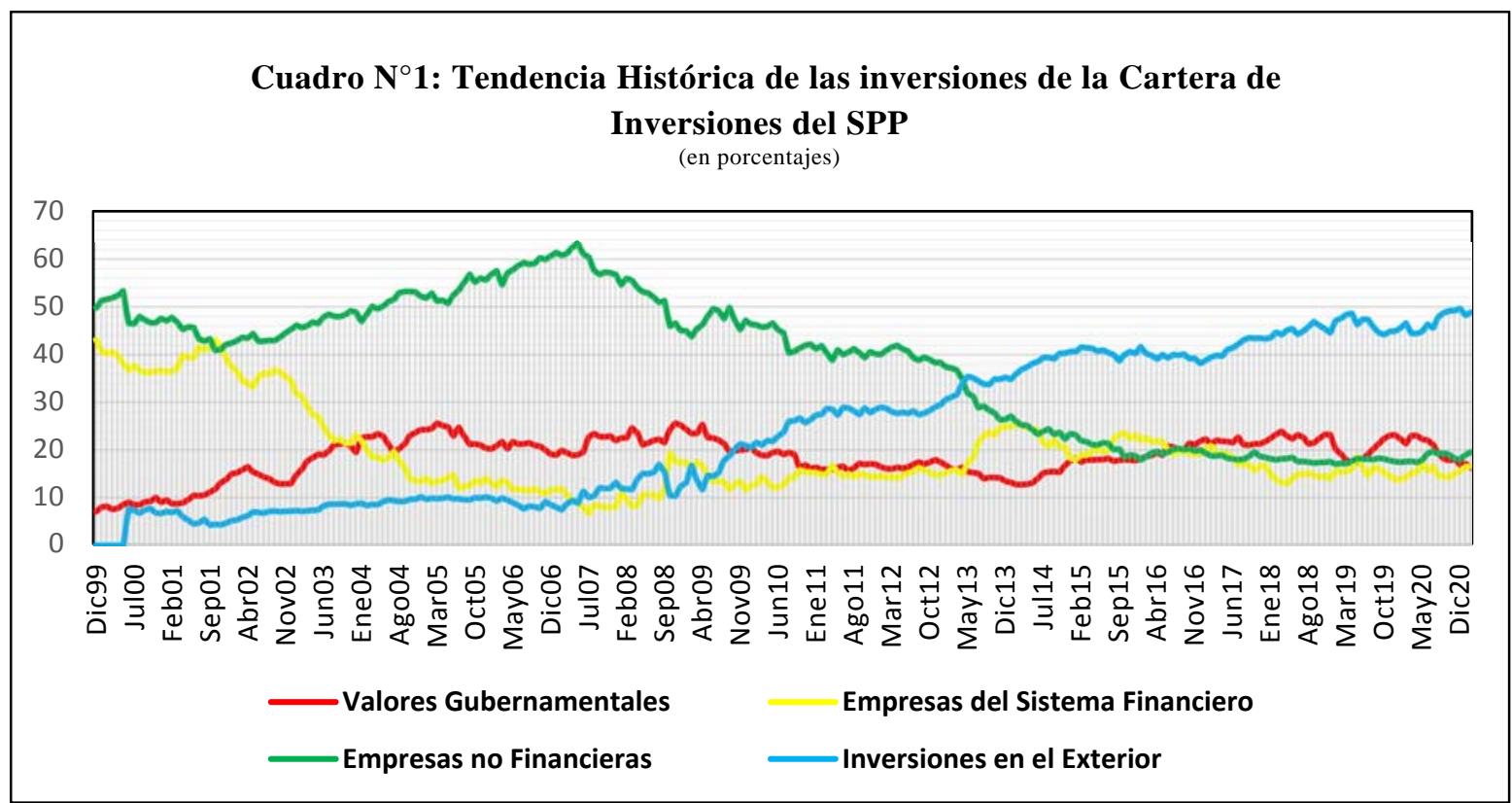

Fuente: BCRP

Las inversiones de los fondos de pensiones en el exterior (color celeste) se observan con una clara tendencia histórica a la alza (aunque se hayan establecido límites de su inversión) y en conjunto es la predominante; en cambio, las inversiones en las empresas no financieras tienen una tendencia hacia la baja desde mayo del $2007 \mathrm{y}$ a partir de marzo del 2014 se ubica en el mismo nivel de las inversiones en valores gubernamentales y empresas del sistema financiero, todas, con una tendencia al estancamiento y permanencia por debajo del $30 \%$. 
Más específicamente, en la época de crisis económica en el periodo de la pandemia, en el que se aplicaron medidas de aislamiento social obligatorio desde el 16 de marzo hasta 30 de junio, se establecieron diversas formas de beneficiar a las empresas nacionales (v.g. ceses colectivos y programas de reactivación económica) y liberaron los ahorros económicos de los trabajadores (v.g. uso de la compensación por tiempo de servicios o retiro de fondos de las AFP), encontramos que no existe una variación sustantiva de las inversiones de los fondos de pensiones por sectores económicos conforme se detalla en el siguiente cuadro:

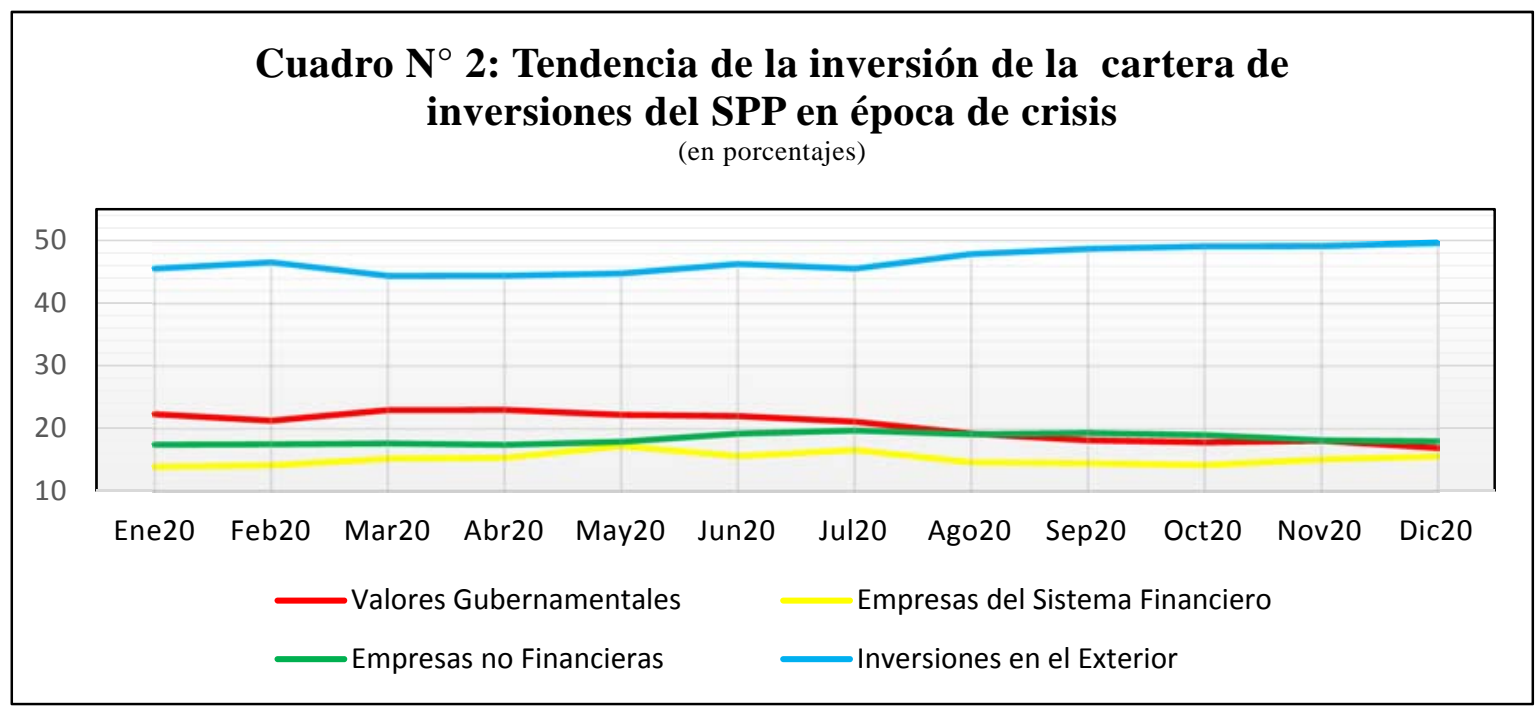

Fuente: BCRP

En época de crisis económica, se advierte que las inversiones de los fondos de pensiones en el exterior se mantuvieron relativamente estables y a partir de julio del 2020 tienen una tendencia leve al alza, mientras que los otros sectores de inversión se mantienen estables hacia la baja por debajo del 25\%. La época de crisis económica confirma la tendencia histórica de la inversión de los fondos de pensiones, en la que, las inversiones en el exterior se muestran determinante.

A diciembre del 2020 se advierte específicamente que el $49.7 \%$ se invierte en el exterior, $16.9 \%$ en el gobierno (Gobierno Central y BCRP), $14.3 \%$ en intermediación financiera, 3.6\% en Energía, 3.5\% en Industria, 2.1\% en Minería, 0.4\% en Inmobiliaria y Construcción y $9.5 \%$ en otros (ver cuadro $\mathrm{N}^{\circ} 3$ ). A pesar de que las inversiones de los fondos de pensiones en nuestro país alcancen el 50.6\%, esta se encuentra altamente dispersa en diversos sectores económico, de los cuales, la actividad económica predominante se encuentra vinculada, principalmente, a sectores especulativos y al endeudamiento del gobierno. 


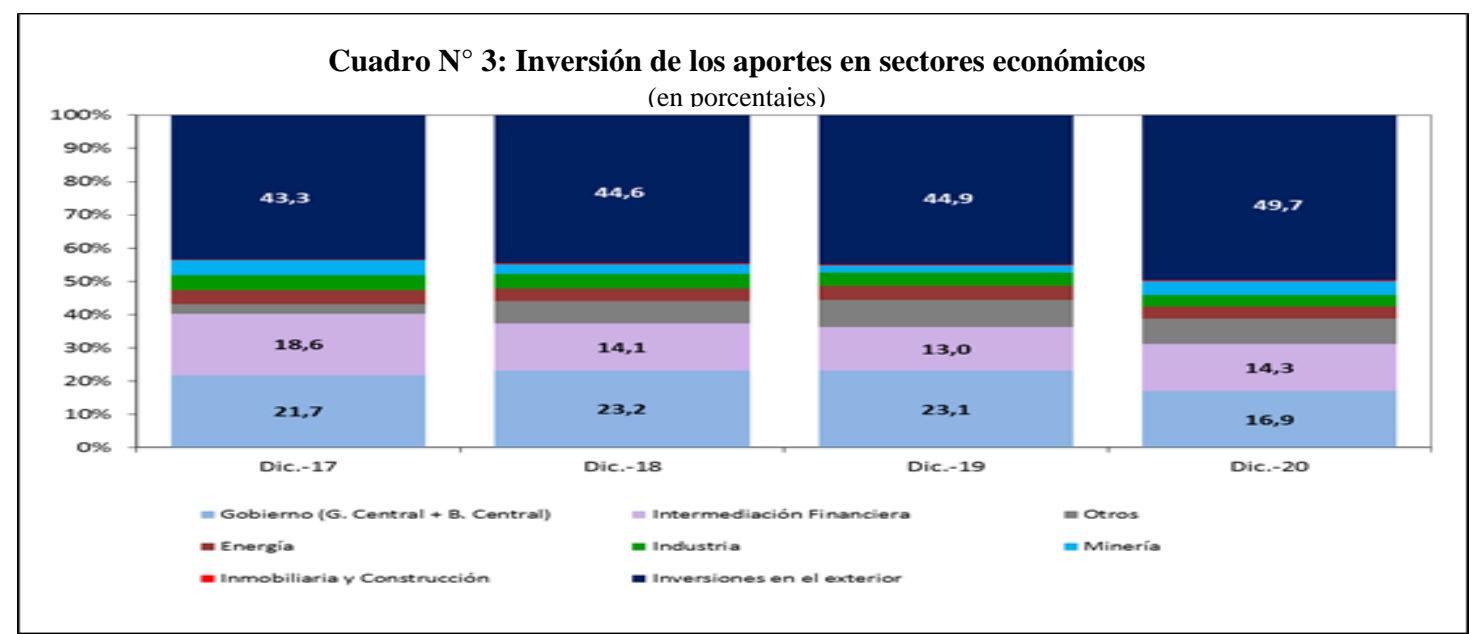

Fuente: SBS

Con ello, se advierte que el capital financiero internacional mantiene su papel dominante sobre el uso de los fondos de pensiones (incluso en épocas de crisis), y con ello, refleja la estructura de dependencia económica de nuestro país, donde los montos mayoritarios de las AFP se invierten en el extranjero (fuga de capitales), los cuales no retornan ni mucho menos se orientan a promover el desarrollo de actividades productivas nacionales; con ello se traza claramente el papel de las AFP en relación con el capital extranjero: Se comporta como su fuente y espacio de acumulación y rentabilidad de manera, cada vez más, amplia y fluida. El Estado en dicha relación, se erige como garante y protector (o minimizador) de los riesgos a los que se expone la actividad especulativa a la que son sometidos los aportes de los afiliados a través de la emisión de sus bonos vía Gobierno Central o BCRP.

\subsection{Comportamiento del capital doméstico}

Ahora, debemos enfocarnos dentro del ámbito nacional y seguir especificando más los sectores domésticos de nuestro país en los que se invierten los fondos de pensiones, a fin de comprender cuál es la naturaleza de las actividades desenvueltas por las AFP. Por ello, a continuación, mostramos el cuadro $\mathrm{N}^{\circ} 4$ donde se describen las principales empresas en las que se invierten los fondos de pensiones: 


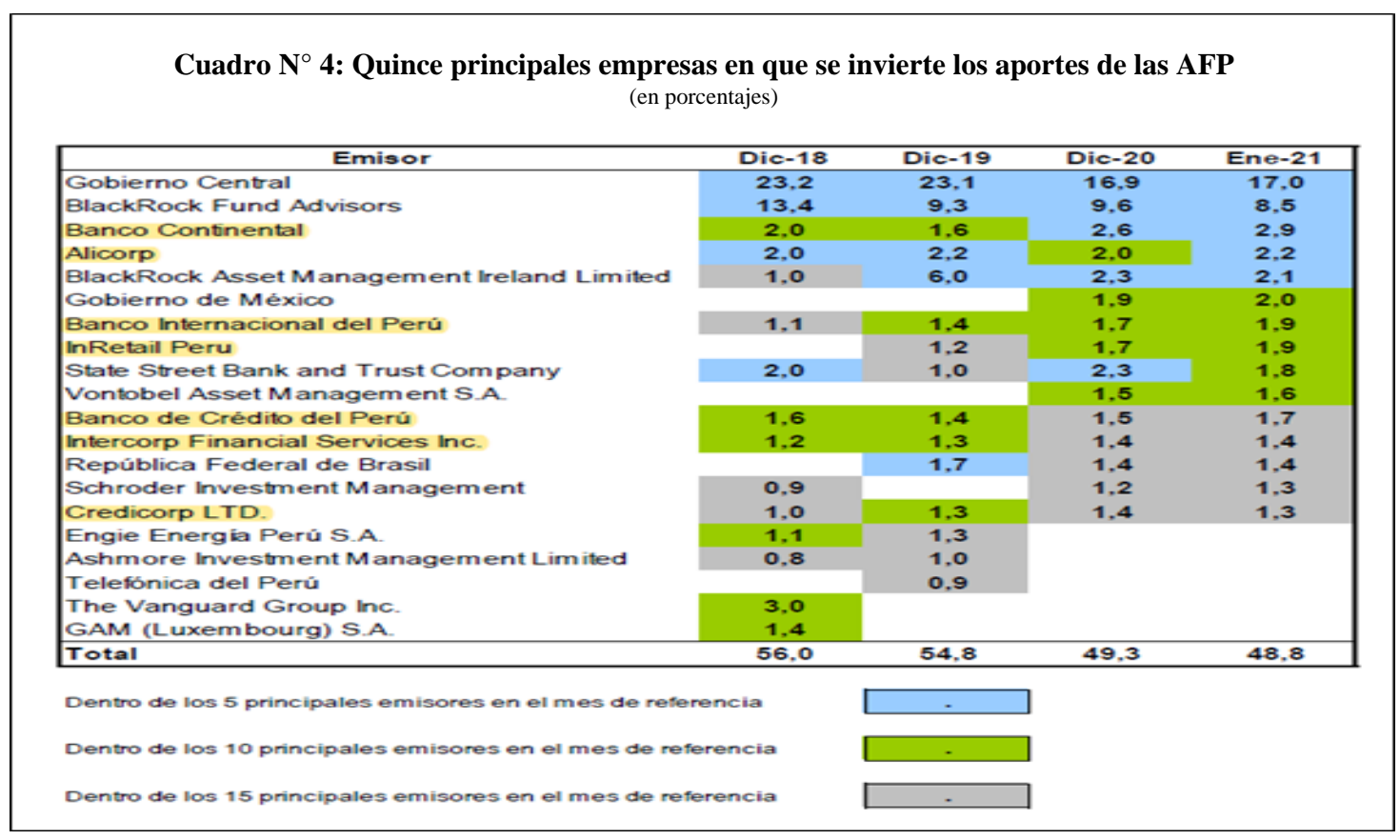

Fuente: SBS

Como se observa, existen siete empresas (sombreadas de color amarillo) sobre el cual recae la absorción del dinero de los fondos de pensiones, ante lo cual corresponde evaluar a qué grupos económicos corresponde:

- La empresa Alicorp (Industria de alimentos y bebidas), Banco de Crédito del Perú y Credicorp LTD. (holding); pertenecen al Grupo Romero.

- Banco Internacional del Perú, Intercorp Financial Services Inc. (holding) e InRetail Perú (almacenes comerciales) pertenecen a Carlos Rodríguez-Pastor.

- Banco Continental pertenece al Grupo Brescia.

Como observamos, las actividades en las que se invierten recaen, principalmente, sobre el capital financiero de los principales grupos económicos de nuestro país, lo que implica un riesgo artificial al que se le impone al sistema de seguridad social en pensiones.

Asimismo, este dinero no se orienta a promocionar o desarrollar (inyectar) al capital nacional productivo, por el contrario, se orienta a un capital especulativo, dejando de lado el sector industrial (industria pesada y ligera), representada por el capital productivo nacional (v.g. MIPYME), dejando de lado con ello la producción de bienes de capital (v.g. maquinarias, motores, entre otros), bienes intermedios (v.g. sustancias químicas básicas, productos de molinería, entre otros) y el proceso de acumulación nacional para garantizar la implementación de políticas sociales, económicos y culturales, que permitan crear fuentes permanentes de ingresos fijos para el financiamiento de un sistema de seguridad social nacional.

Este conflicto, ha generado un grado de dependencia al momento de determinar el destino de las inversiones de los afiliados en periodos de aparente crecimiento (para el mejoramiento de las prestaciones vinculadas a las pensiones) o de crisis (como en el periodo en que nos encontramos), lo cual se explica no sólo por el predominio del capital extranjero en el tipo de inversión de los fondos de pensiones y su tendencia al aumento, sino, por la pérdida de poder económico al que se enfrenta este tipo de capitalistas (que son dueños de las AFP) frente a los otros capitalistas individualmente constituidos en la 
pugna competitiva del sistema económico, lo que los obliga a no detener, y con mayor firmeza en el momento de la crisis actual, el proceso de rentabilidad de "su" capital, de lo contrario, implicaría una pérdida de poder político y económico en el que se encuentran como capitalista individualmente constituidos.

\section{Conflictos estructurales durante la pandemia}

\subsection{Panorama de su desarrollo}

En el contexto de la pandemia, las autoridades de nuestro país emitieron un conjunto de medidas tendientes a la declaratoria de emergencia y al aislamiento social obligatorio (cuarentena); así, mediante Decreto Supremo N 008-2020-SA, del 11 de marzo de 2020, se declaró la Emergencia Sanitaria a nivel nacional y con el Decreto Supremo N $044-$ 2020-PCM, del 15 de marzo de 2020, se estableció el inicio del aislamiento social obligatorio.

Posteriormente, el Estado previó la necesidad de plantear el desconfinamiento que permitiera la reanudación de las actividades pero protegiendo la vida y la salud de los trabajadores conforme a los parámetros fijados mediante el Decreto Supremo $\mathrm{N}^{\mathrm{o}}$ 0942020-PCM del 23 de mayo del 2020 (nueva convivencia social), permitiendo la implementación de diversos reglamentos, lineamiento, protocolos, etc. relacionadas con la seguridad y salud en el trabajo, en ese sentido, se emitieron medidas, entre otras, tales como el Decreto Supremo N 116-2020-PCM del 26 de junio de 2020, que prorrogó sólo el Estado de Emergencia Nacional y fijó las pautas para una cuarentena focalizada y la inmovilización social sólo por horarios a partir del 1 de julio del 2020; después de estas medidas se reanudaron las actividades económicas mediante fases en su totalidad. En la actualidad, a pesar de existir medidas de confinamiento en determinadas fechas y similares, las actividades económicas no se han detenido.

En estas condiciones, se desarrollaron las medidas previsionales vinculadas al SPP, las cuales también se han limitado únicamente al retiro de sumas dinerarias, por parte de los afiliados, para atenuar su estado de necesidad y desprotección, aunque con graves consecuencias para su futuro, expresándose una vez más, las contradicciones irreconciliables entre los dueños del SPP y los afiliados.

\subsection{Dos desembolsos con una misma lógica: Decretos de Urgencias $\mathrm{N}^{\circ} 034-2020$ y $\mathrm{N}^{\circ}$ 038-2020}

En una grave situación de vulnerabilidad, entre los diversos sectores de la población que la padecieron, se hallaron los afiliados al SPP, quienes vieron en sus fondos de pensiones la posibilidad de atender sus necesidades inmediatas ante un sistema económico y social que poco o nada posibilitaba su protección integral en tan crítico contexto a pesar de haberse implementado medidas paliativas con muy poco efecto sobre la población en general.

Hasta el 28 de marzo el 2020, según el Congreso de la República (s.f.1) el gobierno adoptó diversas medidas para mitigar el impacto de la Covid-19 con un gasto público ascendiente a S/ 3,856 millones (USD 1.030 millones), entre los que se encuentran el fortalecimiento de los servicios de salud, sector educativo, ayuda humanitaria, bonos a personas en situación de vulnerabilidad y a las personas con incapacidad temporal, creación del Fondo de Apoyo Empresarial, subsidios en la planilla de empleos, medidas tributarias, cambios regulatorios para liberar la compensación por tiempo de servicios 
(CTS)y suspensión temporal del aporte previsional al SPP (que representaban S/5,500 millones (USD 1,469 millones) en recursos liberados), entre otros; todas estas medidas orientadas a generar mayor liquidez para miles de hogares, ante lo cual, surgió la necesidad, también, de atender al sector de la población que se encuentra en desempleo o sin realizar aportes previsionales obligatorios por 6 meses o más a fin de que obtengan liquidez en el corto plazo y puedan utilizar sus fondos de pensiones para aplacar las consecuencias negativas en su economía por la pandemia.

Aquí es preciso resaltar que, a través del art. 9 del D.U. Nº33-2020 (27/03/2020), se le permitió retirar hasta un la suma de S/ 2,400 (USD 641) de su CTS, la cual no solo desnaturalizaba dichos ahorros forzosos que se hacía semestralmente para que el trabajador afrontara su situación de desempleo, sino que, cargaba únicamente al trabajador, individualmente constituido, quien, tendría que afrontar la pandemia sin apoyo alguno. Por otro lado, la situación de la recaudación del SPP resultó afectada, pues, mediante art. 10 de dicho decreto, también, se estableció la suspensión del aporte previsional del mes de abril, suspensión no considerada para la evaluación al acceso de los beneficios; asimismo, en su art. 11 señaló que los empleadores retengan, declaren y paguen el monto correspondiente al seguro de invalidez y sobrevivencia colectivo del SPP. De esta forma se garantizaba mayor liquidez a los trabajadores para afrontar la situación de pandemia a costa de sus propios ahorros.

Posteriormente, el primer desembolso se establece mediante D.U. N ${ }^{\circ}$ 034-2020 (1/04/2020), vigente desde el mes de abril hasta el 31 de diciembre de 2020 y de carácter intangible frente a terceros, por lo que no fue susceptible de compensación, afectación en garantía, medida cautelar o medida de cualquier naturaleza que tuviera por objeto afectar su libre disponibilidad (numeral 2 de la Primera Disposición Complementaria Final del D.U. N ${ }^{\circ}$ 035-2020); que en su art. 2, señaló dos supuestos para acceder al retiro de los fondos de pensiones:

- Retiro extraordinario de hasta S/ 2,000 (USD 534) de su Cuenta Individual de Capitalización (CIC), siempre que, hasta el 31 de marzo de 2020, no cuenten con acreditación de aportes previsionales obligatorios a la referida cuenta, por al menos seis (06) meses consecutivos (de setiembre del 2019 hasta febrero del 2020).

- En caso la CIC cuente con un monto menor a S/ 2,000 (USD 534), la AFP debe poner a disposición del afiliado, el íntegro de dicha cuenta.

Si bien es cierto, los fundamentos que dieron la posibilidad de retirar los fondos de pensiones, se sustentaron en la solución individual del problema de la crisis económica y la falta de empleo, esta se fue agravando con la implementación de medidas que promovieron los ceses colectivos bajo la figura ficticia de la "suspensión perfecta de labores” a través del art. 3.2. del D.U. 038-2020 (14/04/2020), y reforzado por los art. 4 y 5 del D.S. 011-2020-TR (21/04/2020), los cuales, dispusieron que, excepcionalmente, los empleadores que no pudieran implementar la modalidad de trabajo remoto o aplicar la licencia con goce de haber, por la naturaleza de sus actividades o por el nivel de afectación económica que tenían a la fecha, podrían optar por la suspensión perfecta de labores exponiendo los motivos que la sustentan; lo que a todas luces significó un gran retroceso para el Derecho del Trabajo y el inicio de los despidos masivos encubiertos. Dicha situación se agravó aún más al introducir el silencio administrativo positivo (art. 3.3 del D.U. y 7.5 del D.S. citado), por la cual, los empleadores que solicitaran la suspensión perfecta de labores pero que no encontraran respuesta concreta en el plazo establecido, sea de 30 días para la Autoridad Inspectiva del Trabajo o 7 días para la 
Autoridad Administrativa del trabajo (incluso añadiendo los 5 días referido a la notificación), se entenderá que dichas solicitudes fueron aprobadas, y en consecuencia, operaba la suspensión perfecta de labores.

Para este periodo, el propio Sindicato Único de Inspectores de Trabajo de la SUNAFIL (2020) señalaba que entre el 16 de marzo y el 22 de abril, según cifras estatales, la Superintendencia Nacional de Fiscalización Laboral (SUNAFIL) recibió un total de 6,896 denuncias laborales, asimismo, entre el 14 de abril y el 20 de abril, el Ministerio de Trabajo y Promoción del Empleo (MTPE) recibió un total de 7,124 de solicitudes de suspensión perfecta, las que han afectado alrededor de 84,345 trabajadores. Así, entre denuncias y solicitudes de suspensión presentadas hasta el 22 de abril, hay un total de 14,020 casos laborales (cifra que aumentaría a 15 mil órdenes a verificar para el 8 de junio del 2020). Ante dicho panorama, el número de inspectores de trabajo- según indicaron- era muy escaso: Apenas 661 a nivel nacional, situación que empeora si la mitad de ellos son inspectores auxiliares, quienes no pueden inspeccionar materias que revistan complejidad. Razón por la cual, dicho sindicato solicitó que la figura del silencio positivo sea eliminada.

Las medidas implementadas por el gobierno no sólo abstraían la situación real de las autoridades inspectivas y de trabajo, quienes, no tenían (ni tienen) la capacidad orgánica, económica ni administrativa para atender dichos pedidos, más aún, si los conflictos sociales estaban en aumento; por lo que resultaba irrisorio sostener que la el silencio positivo buscaba una suerte de "facilidad" en el desenvolvimiento de derechos sustantivos o en la agilización de las decisiones administrativas, pues, lo real era que se facilitaba la imposición de la libertad de empresa (derecho sustantivo único) del gran capital para justificar su necesidad de ceses colectivos, pero además, favorecía la no interrumpir el proceso de rentabilidad de capital en condiciones de competencia muy adversas. Así, la normativa laboral encubre una real necesidad del gran capital para extinguir las relaciones laborales, la cual se ve facilitada por la inoperancia estructural fomentada en las instituciones fiscalizadoras de nuestro país.

Estos conflictos agravaron la crisis económica de nuestro país, lo cual, produjo, un nuevo desembolso, que según el Congreso de la República (s.f.2), se justificaba no sólo por el contexto internacional y nacional que expuso a la población en general a una necesidad de liquidez para afrontar la pandemia, sino que, existieron sectores de afiliados desempleados, sin posibilidad de realizar los aporte previsionales por 1 mes o más, encontrándose en posible suspensión perfecta de labores; razones por las cuales- a juicio del Congreso-, se hizo necesario la utilización de parte de sus fondos de pensiones para que atendieran sus necesidades de subsistencia y las de su familia.

De esta forma, el segundo desembolso se manifiesta a través del Decreto de Urgencia $N^{\circ} 038-2020(14 / 04 / 2020)$, que excluye al universo de personas comprendidas en el primer desembolso (D.U. N ${ }^{\circ}$ 034-2020) y, según su art. 10.7, adopta un carácter intangible. Además de ello, su art. 10 establece los supuestos y los montos que se podían retirar:

- Por única vez, el retiro extraordinario de hasta S/ 2,000 (USD 534) de la CIC, siempre que al momento de la evaluación de la solicitud el trabajador se encuentre comprendido en una medida aprobada de suspensión perfecta de labores prevista en el marco legal vigente. 
- Por única vez, el retiro extraordinario de hasta S/ 2,000 (USD 534) de la CIC, siempre que al momento de evaluación de la solicitud no cuenten con la acreditación del aporte previsional obligatorio correspondiente al mes de febrero o marzo del 2020.

- Por única vez, el retiro extraordinario de hasta S/ 2,000 (USD 534) de la CIC cuya última remuneración declarada o la suma de estas percibidas en un solo periodo sea menor o igual a S/ 2,400 (USD 641), siempre que al momento de evaluación de la solicitud cuenten con la acreditación del aporte previsional obligatorio al mes de febrero o marzo del 2020.

Su vigencia, según su art. 12, será en tanto dure la emergencia sanitaria a nivel nacional declarada mediante Decreto Supremo No 008-2020-SA, así como el Estado de emergencia nacional establecido mediante Decreto Supremo No 044-2020-PCM, y sus prórrogas, el cual se extendió hasta el 5 de abril del 2021.

Como observamos, los desembolsos establecidos por el gobierno, buscaron otorgar liquidez a los afiliados, encontrándolo principalmente en los fondos de pensiones, cuyo desembolso terminó por demostrar su naturaleza: Montos dinerarios ahorrados forzosa e individualmente. Los retiros de los fondos de pensiones ahorrados en la CIC representaron una salida del sistema económico para aminorar la crisis a costa de los afiliados, quienes, se hicieron cargo de su situación de desamparo con sus ahorros para su jubilación.

\subsection{El retiro del $25 \%$ : La ley $\mathrm{N}^{\circ} 31017$}

El aislamiento social obligatorio hasta el mes de mayo se mantuvo en función de la evolución de los contagios existentes, lo que conllevo a la agudización de la crisis económica y sanitaria de la población en general. Esto obligó a que las medidas de confinamiento se extendieran hasta el 24 de mayo del 2020 (D.S. $\mathrm{N}^{\circ} 051-2020-\mathrm{PCM}, \mathrm{N}^{\circ}$ 064-2020-PCM, N 075-2020-PCM y Nº83-2020-PCM). En este periodo, nuevamente se desarrollaron debates en torno a la necesidad de dotar de liquidez a la población a fin de permitir la futura reactivación económica, ante lo cual, el sector de afiliados a las AFP, obtuvieron la posibilidad de realizar un nuevo retiro de sus fondos de pensiones.

El Congreso de la República (2020a), desde el 24 de marzo hasta el 1 de abril del 2020 desarrolló diversos proyectos de ley para evaluar la necesidad de habilitar a los afiliados al SPP los retiros de los fondos de las CIC, las cuales, tuvieron, entre otros, los siguientes fundamentos:1) Al marzo del 2020, países como Italia, España, Estados Unidos y China fueron los países con altos índices de contagios, y en el Perú, se calculaba 1065 contagios, 190 hospitalizados y 30 fallecidos; situación que requería adoptar medidas a fin de prevenir el aumento de contagios, 2) La crisis económicas se vieron agudizadas por las tensiones comerciales y políticas entre China y EEUU, las cuales, preveían medidas de política fiscal por parte de la Reserva Federal de EEUU,3) La crisis económica comenzó a perjudicar el valor de los fondos de pensiones, aunado a que las comisiones cobradas por las AFP se mantuvieron intactas debido a su diseño, pues, estas no dependen de las ganancias o pérdidas que ocurriera en los fondos de la CIC, además, en dicho contexto, los fondos con alta volatilidad estaban expuestas a pérdidas que los afiliados soportaban y no podían evitar, por más que exista un procedimiento para trasladar sus fondos a un tipo de fondo menos riesgoso, 4) Ante las medidas de aislamiento social obligatorio y estando a que el Estado no tiene la capacidad para otorgar recursos inmediatamente a la población y sólo ha establecido algunos paliativos (v.g. bonos, 
canastas, etc.), se necesitaba adoptar medidas tendientes a dar liquidez a los afiliados a través de sus propios fondos y que generara un movimiento de capitales en la economía nacional, la que a su vez, pueda permitir al Estado recaudar impuestos, 5) El Ministerio de Economía y Finanzas (MEF), en su presentación ante el Congreso de la República del 31 de marzo del 2020, señaló que existen aproximadamente más de 3 millones de afiliados con un fondo acumulado por debajo de la suma de S/ 5,000 (USD 1,335), a los que, si se les aplica el 25\% de retiro de su fondo (propuesta legislativa del nuevo desembolso), recibirían en promedio S/ 391 (USD 104); lo que describe un panorama donde los afiliados, sin necesidad de realizar el retiro del $25 \%$ de sus fondos, igualmente, no recibirían una pensión adecuada.

Una vez en el Pleno, el Congreso de la República (2020b) advirtió, además de la campaña mediática que las AFP desplegaron a fin de mostrar la situación catastrófica que generaría el potencial retiro, que el BCRP (vía Julio Emilio Velarde Flores), la Superintendencia de Banca, Seguros y Administradoras Privadas de Fondos de Pensiones (SBS) y el Estado (vía Presidente, Martín Alberto Vizcarra Cornejo y Ministra de Economía y Finanzas, María Antonieta Alva Luperdi), tuvieron una posición favorable a las AFP. Además de ello, las AFP señalaron que, de aprobarse los proyectos de ley de retiro de aportes, venderían los bonos del Estado para obtener liquidez y cumplir con las obligaciones previsionales producto del retiro; a pesar de que las inversiones en el exterior alcanzaban casi el $44 \%$ del total de la cartera administrada. El objetivo de la medida, que se deduce a lo largo de los debates, es que los afiliados tengan dinero para afrontar y recuperarse de la crisis económica, asimismo, la lógica que empieza a hegemonizar en los discursos de los congresistas es la de que, los aportes de los afiliados es dinero suyo, y por tanto, no tiene nada que ver los objetivos previsionales futuros. Asimismo, el nuevo retiro de fondos no podría ser contradictorio con las medidas anteriormente dispuestas por el gobierno. En el debate también se advirtió la necesidad de realizar reformas integrales al sistema previsional tanto público como privado.

A pesar de los conflictos suscitados, el nuevo retiro se implementó a través de la Ley $N^{\circ} 31017$ (1/05/2020) o Ley que establece medidas para aliviar la economía familiar y dinamizar la economía nacional en el año 2020 (medida aprobada por el Congreso), la cual, mantuvo también su condición de intangible (art. 1 de la Ley $\mathrm{N}^{\circ} 31022$ ) y precisó que los afiliados beneficiados por el D.U. N 34-2020 podrían retirar sus fondos bajo esta nueva norma pero descontando la suma recibida en ocasión de él y manteniendo los límites previstos. Así, esta Ley dispuso las siguientes cantidades y requisitos para retirar sus fondos de pensiones:

-Retiro de hasta el 25\% del total de sus fondos acumulados en la CIC. Con tope mínimo de 1 UIT (USD 1,148) y máximo: 3 UIT (USD 3,446). La entrega se realizará en dos desembolsos del 50\% cada uno.

-En el caso de que el afiliado tenga un fondo acumulado total en CIC igual o menor a 1 UIT (USD 1,148), el retiro será del 100\% y en un solo desembolso.

Según se señala, en su art. 2.4, los afiliados deben solicitarlo en el plazo máximo de 60 días calendario de publicado el procedimiento operativo por parte de la Superintendencia de Banca, Seguros y AFP, el cual fue publicado mediante Resolución SBS $N^{\circ}$ 1352-2020, con fecha 11 de mayo del 2020, la cual, en su artículo séptimo, dispuso la vigencia de dicha resolución a partir del 18 de mayo de 2020, lo que indica que, las solicitudes se tendrían que realizar hasta 16 de julio del 2020. 
La emisión de esta norma estuvo en el vórtice del conflicto entre el poder ejecutivo y legislativo, de ahí que su promulgación no fuera realizada por el Presidente de la República, además, se desenvolvieron los debates en torno a la necesidad de la reforma de los sistemas público y privado de pensiones. Esto explica cómo, progresivamente, por un lado, los sectores del Estado y sus representantes, se ven forzados a atender la situación de los afiliados y de atenuar las fórmulas de retiros a fin de aminorar el perjuicio económico al SPP, atendiendo, como siempre, a los requisitos expuestos por los dueños de las AFP; y por el otro, los políticos, cuyo pragmatismo, los vincula a propuestas cortoplacista y discursos formales de "reformas" que, en última instancia, inciden sólo en la estructura técnica (paramétricas o estructurales, en términos de la OIT).

Además, resulta importante resaltar que, durante todo este proceso, las AFP, a decir de Durand (2020), habrían desarrollado una estrategia para conseguir el respaldo económico del Estado y el Banco Central de Reserva del Perú (BCRP) de la siguiente manera:

En lugar de proceder a vender valores en el mercado mundial, y ante las expectativas de los pensionistas de sacar sus fondos, las Cuatro Hermanas (AFP Prima, Integra, Profuturo y Habitat), optaron por pedirle ayuda al Estado. Sí, ese mismo Estado que consideran burocrático, ineficiente, una traba al desarrollo.

La movida era inusual. El BCR y el B[N] están para servir los intereses de la economía pública, no la privada. Las AFP, con la ayuda de [Roberto] Abusada [del Instituto Peruano de Economía], el economista neoliberal más influyente y antiguo del país, en coordinación con Giovanna Prialé, la presidente del gremio de AFP, comenzaron a barajar alternativas. Una de las primeras movidas fue sugerirle a Alva que fuera el BN quien le diera préstamos en soles para ir financiando los retiros. [María Antonieta]Alva [Luperdi, Ministra del MEF] aceptó inmediatamente y envió a José Carlos Chávez a presionar al BN. Luis Alberto Arias se negó, no solo porque no está dentro de sus funciones dar este tipo de servicios sino porque tal propuesta comprometía las finanzas del banco. La presión para que aceptara se hizo a través de Chávez.

Malogrado el Plan A, pasaron al Plan B. pero no olvidaron lo que consideran una afrenta. El BCR decidió apoyar un plan para darles fondos que favorecen a las AFP, medida que nunca antes se ha tomado y que es posible exceda sus atribuciones de ley. Julio Velarde aduce que se podía caer el mercado, indicando un temor que no tiene base. Lo lógico es que las AFP vendan activos en el exterior, no en el Perú. Es un pobre argumento.

Esto suscitó una diversidad de cuestionamientos sobre el papel del BCRP en relación a las AFP, ya que, se le asoció inmediatamente a una instrumentalización por parte de las AFP para salvaguardar sus intereses, por ello, el Banco Central de Reserva del Perú (2020a), mediante nota informativa, señaló lo siguiente:

Las REPO [u Operaciones de recompra de títulos, son compras temporales de activos de alta calidad que hará el BCRP, específicamente en dólares, a las AFP, con la condición de que éstas los recompren al BCRP dentro de un plazo establecido] con las AFP no benefician a las AFP ni a sus accionistas, que tienen un patrimonio separado al del fondo de pensiones, sino que ayudan a preservar el valor del Fondo de los afiliados.

Esta medida se ha dado para evitar la potencial venta masiva de S/ 35 mil millones [USD 9,351 millones] de bonos del Tesoro para pagar los retiros de hasta un 25\% de los fondos de los afiliados a las AFP. Estas ventas en un período muy corto hubieran desvalorizado estos bonos, perjudicando a los afiliados y también causando una elevación no deseada de las tasas de interés de largo plazo en soles en un contexto que el Banco Central ha reducido a niveles mínimos su tasa de interés de política monetaria.

En efecto, el alza de la tasa de interés del bono del Tesoro peruano -al ser una guía para el resto de tasas de la economía- hubiera elevado las tasas de interés de operaciones de largo plazo del sector privado, como es el caso de las hipotecas.

La desvalorización abrupta de los bonos del Tesoro Peruano habría reducido la confianza de los inversionistas extranjeros sobre estos títulos, lo que hubiera provocado una salida de capitales y 
presiones al alza del tipo de cambio. Es importante destacar que la sola publicación de la norma que ampliaba las REPO a las AFP con bonos del Tesoro evitó dicho efecto.

Entonces, lo que llama la atención es por qué se optó por las REPO y no por la liquidación de activos en el exterior. La respuesta la encontraremos en la propia lógica de la rentabilidad del capital bajo el control de las AFP, que evaluando el menor impacto sobre su rentabilidad, encontró que, la liquidación de activos en el exterior hubiera generado una mayor disminución del valor de los activos de los fondos de pensiones por el alto grado de volatilidad al que se exponen los dólares en el periodo de crisis, otorgando menores sumas en soles a los que retiraran sus fondos, además, otro efecto sería el alza del interés sobre la economía del país a causa de la desvalorización de los bonos del Tesoro Público que habría vendido las AFP. La lógica de la rentabilidad del capital se impone para atender la vía menos costosa pero, a su vez, refleja nuestra estructura economía subdesarrollada y dependiente: La imposible ruptura con el capital financiero internacional, no por acto de voluntad que las AFP pudieran o no efectuar, sino por la naturaleza misma del capital que representa las AFP, quienes se encuentran imposibilitados de liquidar los activos del exterior porque encuentran un mayor perjuicio económico en su rentabilidad y en consecuencia, el riesgo de perder la posición de dominio en el mercado de las pensiones, por lo que, dada su relación histórica con las instituciones del Estado, encuentran una alternativa menos gravosa para suplir o atenuar dicha pérdida: Las REPO, la cual, deja intacto la inversión en el exterior y nos señala el carácter subordinado de las AFP al capital internacional.

Como se advierte, ni el Estado (o sus instituciones) ni los políticos pragmáticos, proponen una salida real al conflicto, sino su agudización, pues, por un lado, el Estado y su subordinación a las AFP, y por el otro, los políticos pragmáticos, con una visión individualista y coyuntural del problema, no pueden dar una salida real a los problemas previsionales del país, por el contrario, se refuerza el individualismo ahorrista y se deja fuera de discusión el papel que debería tener los fondos de pensiones en el desarrollo económico e industrialización de nuestro país a fin de garantizar fuentes permanentes de ingresos para atender a los riesgos sociales de forma integral. Para ambos sectores, el problema se encarrila únicamente a discutir los tipos de afiliados a beneficiar, qué prestaciones debe recibir y cuánto deberá ser el monto de pensiones, debate que refleja la miseria de los ideólogos de la seguridad social dominante.

\subsection{El retiro extraordinario: Ley $N^{\circ} 31068$}

Durante los cinco meses posteriores a la emisión de la Ley $N^{\circ} 31017$ y $\sin$ aislamiento social obligatorio, se agudizaron los conflictos entre el poder ejecutivo y legislativo, llegando a la crisis política en el que se vería envuelto el presidente de la república de aquel entonces, Martín Alberto Vizcarra Cornejo, por estar vinculado a actos de corrupción.

En ese panorama, la Comisión de Economía, Banca, Finanzas e Inteligencia Financiera (2020), en su dictamen en mayoría, sostuvo la necesidad de la emisión de una norma que volviera a permitir el retiro de las pensiones, teniendo en cuenta que esta debería realizarse de forma moderada y progresiva a fin de evitar la pérdida del valor de los fondos y la generación de inflación por la liquidez; en ese sentido tomó en cuenta los siguientes aspectos:

1. Conforme a los informes de la Organización para la Cooperación y el Desarrollo Económico (OCDE), existirá: a) Un descenso en el valor de los activos y retiros de los 
fondos de pensiones desde la caída de los mercados financieros, b) un incremento en los pasivos por la caída de las tasas de interés y retiro de los ahorros previstos con fines previsionales, c) Baja capacidad de contribuir al retiro de los planes de ahorros por parte de individuos al ver la reducción de sus salarios y pérdidas del empleo, d) Disrupciones operativas producto del trabajo remoto, e) Cyber ataques, fraudes y estafas dirigidas a individuos, reguladores, supervisores y esquemas de administración de fondos de pensiones, f) Reducción en los ahorros y tasas compuestas de interés como resultado de las medidas previstas para el alivio en el corto plazo que puedan tener impacto negativo en el largo plazo, especialmente en el retiro de la adecuación de los ingresos. Ante lo cual, la política previsional que tiene como objetivo limitar la materialización de pérdidas de inversión, asegurar la insolvencia de los planes de retiro, contribuciones y subsidios y las disrupciones operativas a domicilio son calificadas como buenas políticas, mientras que, brindar alivio de corto plazo con riesgo de largo plazo es designada como política negativa. Se destaca de ello que, se prevé un conflicto intraafiliados, donde los fondos de poca volatilidad de los afiliados servirían para financiar la liquidez requerida para los retiros de los fondos.

2. De los afiliados aportantes activos y los que tienen más de 6 meses de no aportar (en total 5,409 millones de personas), se puede apreciar que el 19\% (poco más de un millón de afiliados) dispuso de la totalidad del saldo de sus CIC tras la disposición del 25\% aprobado por el Congreso de la República retirando un total de S/ 1,342 millones (USD 358 millones), el 57\% retiró hasta S/ 18,209 millones (USD 4,865 millones), quienes dejaron un saldo vigente de S/ 79,547 millones (USD 21,254 millones), mientras que el 26\% restante no dispusieron en lo absoluto de sus fondos, dejando un saldo vigente en sus CIC de S/ 46,721 millones (USD 12,483 millones); se espera que en un eventual aprobación de disposición del 100\% de los fondos de las AFP, este 57\% de afiliados (más de 3 millones de personas), dispongan del total de sus fondos, haciendo un retiro total de S/. 79,547 millones (USD 21,254 millones). Además, se advierte que, los gastos, conforme al escenario del retiro del 95\%, podrán destinarse al consumo y no en gastos superfluos (Bosch et al., 2020). La retiro de los fondos de pensiones originará que el afiliado, y en cierto grado el Estado, asuma el riesgo de longevidad, comportamiento y retorno.

3. Los retiros del 25\% (conforme a la Ley $\mathrm{N}^{\circ}$ 31017), conforme a la información de la SBS, señala que, los aportantes que retiraron todo el dinero de su CIC en su mayoría tienen entre 20 y 40 años, y quienes retiraron dinero de su CIC pero dejaron un saldo, se concentrar en individuos entre 25 y 50 años de edad; de estos últimos, S/ 18 mil millones (USD 4,809 millones) han sido retirado y han dejado como saldo un poco más de S/ 80 mil millones (USD 21,375 millones). Estos últimos asegurados serían los candidatos para los siguientes retiros de fondos de aprobarse la Ley.

4. Se advierte, conforme a los datos de las Asociación de las AFP que, del 26\% del total de afiliados, durante 12 meses no han realizado aportes, quienes en conjunto retiraron S/ 13,842 millones. Al 14 de octubre del 2020, el monto de los afiliados al SPP con más de 12 meses sin aportar se rige por: a) Hasta 1 UIT (USD 1,148): 1’055,010 afiliados, b) 1 a 2 UIT(USD 1,148 a 2,297): 316, 320 afiliados, c) de 2 a 4 UIT (USD 2,297 a 4,595): 495,090 afiliados, y d) más de 4 UIT: 10,384; así, los beneficiarios de hasta 4 UIT (USD 4,595)serían alrededor de 1’866,420 afiliados. Se advierte que los montos de hasta 1 UIT (USD 1,148) son los predominantes y el panorama de futuras 
pensiones adecuadas resulta inviable para los afiliados que retiren sus fondos aun así se abstengan de realizar dichos retiros, pues, sus montos acumulados son muy bajos. Se calcula que se inyectaría a la economía de las familias un monto de S/ 14,575 millones (USD 3,894 millones).

Lo que vino posterior a dicha discusión sobre la necesidad de los retiros de los fondos privados de pensiones, estuvo enlazada con el contexto de la aprobación de la vacancia contra Martín Alberto Vizcarra Cornejo, llevada cabo en la sesión virtual del Pleno del Congreso del 9 de noviembre de 2020, mediante Resolución del Congreso 0012020-2021-CR (10/11/2020) que consagró dicha decisión; asumiendo como presidente efímero, Manuel Arturo Merino de Lama, del 10 de noviembre hasta el 15 de noviembre de 2020, quien ocupó dicho cargo con graves cuestionamientos y en un ambiente político caracterizado por un alto grado de represión a las protestas que se manifestaron inmediatamente por estos acontecimientos, originando el fallecimiento de manifestantes y el rechazo generalizado de la población. El 16 de noviembre de 2020, Francisco Rafael Sagasti Hochhausler, fue elegido presidente del Congreso de la República del Perú y, por sucesión constitucional tras la renuncia de Manuel Arturo Merino de Lama, asumió la Presidencia de la República; igualmente, los conflictos no dejaron de cesar y explosionó la lucha de contra la Ley $\mathrm{N}^{\circ} 27360$ o Ley que aprueba las normas de promoción del sector agrario (que posteriormente fue derogada por la Ley $\mathrm{N}^{\circ} 31110$ del 31 de diciembre del 2020), donde también existieron manifestantes muertos.

En este contexto muy convulsionado, se promulgó la Ley $N^{\circ} 31068$ (18/11/2020) o Ley que faculta el retiro de los fondos privados de pensiones en el contexto de la pandemia COVID-19, la cual señaló los siguientes montos y requisitos para retirar los fondos de pensiones:

- Retiro extraordinario de hasta 4 UIT (USD 4,595) del total de sus fondos acumulados en su CIC, para lo cual, el afiliado, que hasta el 31 de octubre de 2020, deberá no contar con acreditación de aportes previsionales a la CIC, por al menos doce (12) meses consecutivos.

- Retiro excepcional facultativo de hasta 1 UIT (USD 1,148), para lo cual, el afiliado, no deberá registrar aportes acreditados en el mes de octubre de 2020 y que no sean beneficiarios de lo establecido anteriormente.

- Retiro por salud extraordinario de hasta 4 UIT (USD 4,595) en un solo retiro de los fondos de las CIC, para lo cual, el afiliado que deberá estar o no aportando y padeciendo enfermedades oncológicas (enfermedades tumorales, vg. Cáncer de piel, Tiroides, Colon, Pulmón, Próstata, de Ovario.) diagnosticadas por una institución prestadora de servicios de salud (IPRESS), que se encuentre registrada en el Registro Nacional de Instituciones Prestadoras de Salud (RENIPRESS) de la Superintendencia Nacional de Salud (SUSALUD) y que hayan registrado la autorización sanitaria para la práctica de la Unidad Productora de Servicios de Salud (UPSS) de oncología y/o hematología clínica, según corresponda.

La única exclusión de este beneficio, según art. 1, se hizo sólo a quienes califiquen para acceder al Régimen de Jubilación Anticipada por Desempleo. Asimismo, en su art. 3 , se señaló el carácter intangible de los retiros, pero realiza excepciones, indicando que no se aplica a las retenciones judiciales o convencionales derivadas de deudas alimentarias, hasta un máximo de $30 \%$ de lo retirado. Por otro lado, en su Primera Disposición Complementaria Final, establece que los afiliados deben solicitarlo en el plazo máximo de 90 días calendario de la vigencia del procedimiento operativo por parte 
de la Superintendencia de Banca, Seguros y AFP, el cual fue publicado mediante Resolución SBS No 2979-2020, con fecha 28 de noviembre del 2020, la cual, en su Artículo Octavo dispuso la vigencia de dicha resolución a partir del 9 de diciembre de 2020, lo que indica que, las solicitudes se tendrían que realizar hasta 13 de marzo del 2021.

Durante este periodo, como advertimos, los problemas económicos ya agudizados, se ven expuesto a un conflicto político, donde se ventilan, ante la sociedad, los conflictos entre los representantes de las facciones burguesas, constituidos en el poder ejecutivo, y los partidos política pragmáticos y oportunistas atomizados, cuya línea política indefinida sólo los lleva a determinar sus acciones en función de caudillos, electorerismo o coyunturalismo; en esta pugna de intereses, la clase trabajadora en general, y los sectores de afiliados al SPP, no vieron modificada sustantivamente su situación, pues antes durante y después de la pandemia (con o sin vacancia), sus condiciones materiales de existencia precaria se mantuvieron intactas.

\subsection{Efectos a largo plazo de los retiros de los fondos de pensiones}

En los países del tercer mundo, donde no existe Estado- Nación (ni en potencia ni perspectiva), condiciones materiales mínimas de desarrollo y progreso, bases económicas democráticas burguesas ni tampoco bases materiales que erijan procesos de industrialización del país; se generan condiciones para que exista un alto grado de desintegración social y desprotección social absoluta y precaria, lo que lleva consigo, a una visión cortoplacista fomentada a los afiliados del SPP y a la carencia de una política previsional nacional articulada. En nuestro país, esto se consolidó y expandió en la reestructuración del Estado burgués en la década de 1990 que dejó su sello impregnado en el fomento de un tipo de política previsional: Las AFP.

Este panorama ha sido agudizado por los diversos retiros de los fondos de pensiones, en el que los afiliados al SPP se han visto obligados por la necesidad a cubrir su situación de vulnerabilidad con sus propios ahorros previsionales, explicitando la real naturaleza del SPP, la cual, no sólo se desnaturaliza por la política pública sino que esta misma es la expresión de la desnaturalización desde su implementación, expansión y consolidación; en este panorama, los efectos de los conflictos estructurales de las AFP, a largo plazo, recaerán principalmente sobre la posibilidad de cumplir las futuras obligaciones previsionales y la economía nacional.

El Banco Central de Reserva del Perú (2020b) ha señalado que, a raíz de la crisis de la Covid-19, donde se aprobaron retiros de pensiones tanto por el Poder Ejecutivo (D.U. N 034-2020 y 038-2020) como el Poder Legislativo (Ley 31017), ha traído como resultado que para octubre del 2020, el valor de la cartera administrada por las AFP (S/ 154,307 millones o USD 41,229 millones) se redujera en S/ 20,658 millones (USD 5,519 millones) con respecto al cierre de 2019, dado los masivos rescates de las cuotas realizados por los afiliados. De ese flujo, un total de S/ 21,560 millones (USD 5,760 millones) corresponden a los retiros netos -rescates de cuotas menos aportes- (reducción de $12.3 \%$ con relación al cierre de 2019), parcialmente compensados con un flujo positivo de S/ 901 millones (USD 240 millones) asociados a la rentabilidad del portafolio (0,5\% adicionales con respecto al cierre de 2019). Así, los afiliados de las AFP realizaron retiros por S/ 24263 millones (USD 6,482 millones) de sus fondos de pensiones (3,2\% del PBI) y para atender estos rescates, las AFP liquidaron inversiones en el exterior por S/ 10 mil millones (USD 2,671 millones), en bonos soberanos por S/ 8 mil millones (USD 
2,137 millones) y en otras inversiones locales y contribuciones netas por $\mathrm{S}$ / 6 mil millones (USD 1,603 millones) (p. 53).

Además, resulta fundamental analizar los grupos de afiliados agrupados en función de la edad a fin de evaluar qué grupo prevalece como sector vulnerable y las posibles medidas a futuro a dilucidar, para lo cual, tenemos el siguiente cuadro:

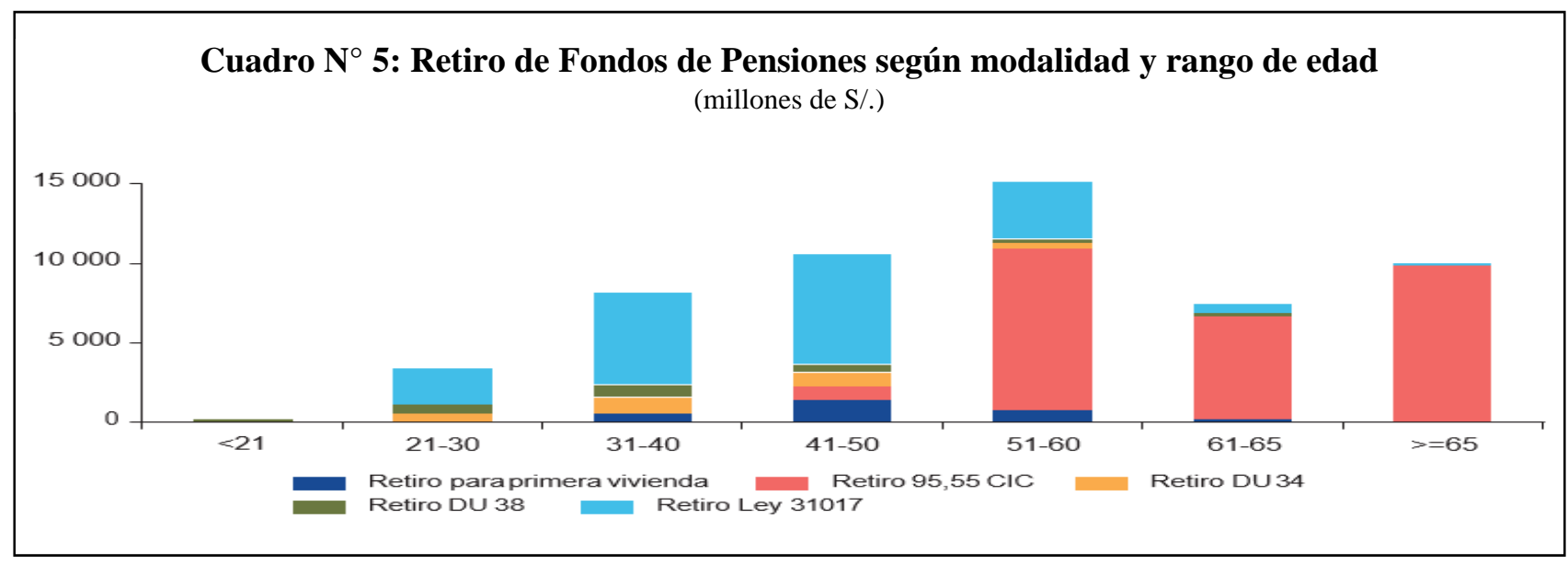

Fuente: SBS

Como lo advierte el Banco Central de Reserva del Perú (2020b), los retiros del 95\% se concentran en afiliados que se encuentran o están en los afiliados próximos a la edad de jubilación, asimismo, y relacionado específicamente al contexto de la pandemia, el retiro mediante Ley 31017 se concentra en el grupo etario de 30 a 50 años, quienes representan el 61\% de los afiliados al SPP y que, debido a su retiros realizados, perderán en valor presente hasta el $60 \%$ de sus fondos previsionales, y además, tendrán dificultades para volver a acumular fondos suficientes para obtener una pensión adecuada; este efecto es aún más severo para los 2,1 millones de afiliados que no registran fondo alguno en su CIC luego de realizar retiros durante el confinamiento social (marzo- junio). Estos afiliados se enfrentan a un riesgo elevado de caer en situación de pobreza en la etapa de vejez y perder el acceso a las coberturas de Essalud.

En dicha situación, debemos advertir que, si bien es cierto que con el retiro de los fondos acumulados de ciertos sectores de afiliados les será imposible acceder, en un futuro, a una pensión adecuada, también lo es, que, a pesar de no haberlo retirado, estos sectores tampoco hubieran recibido una pensión adecuada. Entonces, ante estas alternativas, se impone la necesidad inmediata del afiliado para afrontar su situación inmediata. Lógica que no es superada por el propio diseño del SPP que lo obliga a elegir una situación “óptima” de subsistencia.

La Federación Internacional de Administradoras de Fondos de Pensiones (FIAP), donde, la Asociación de Administradoras Privadas de Fondos de Pensiones de nuestro país es socia plena, ha realizado un estudio, a través de Acuña et al. (2021), señalando que, el diseño de los retiros de fondos de pensiones en nuestro país, revela una falta de focalización en quienes más lo necesitan, un incentivo tributario a realizar retiros y una falta de claridad respecto de cómo se repondrán dichos fondos (aumento temporal de la tasa de cotización o aumento de la edad de jubilación, o una combinación de ambos). Asimismo, ha señalado otras causas, adicionales a las ya expuestas aquí, que consisten en: 
- Valoración de la pensión como propiedad individual de los afiliados, donde, el 79\% de los peruanos dieron su respaldo al proyecto de ley de retiro del $25 \%$ de los fondos.

- El principal activo vendido entre febrero y noviembre del 2020 fueron los bonos del gobierno con una diferencia de USD 2,124 millones, depósitos bancarios con USD.378, otros instrumentos de renta fija nacional con USD 290, bonos bancarios con USD 239 y depósitos a plazo del banco central con USD 26 millones. Por otra parte, la renta variable y la inversión extranjera vieron aumentos por USD 28 y USD 427 millones, respectivamente.

- Las compañías de seguro no realizarán un mayor aporte para compensar los montos retirados sino que estos disminuirán el monto de pensiones de invalidez y sobrevivencia, incrementando el riesgo para el sector asegurador por los bajos beneficios que se pagan.

- Reducción de los ahorros acumulados, de los números de trabajadores cubiertos y el incremento del gasto estatal en pensiones.

- Disminución de la tasa de ahorro, aumento del riesgo país (incertidumbre de los agentes financieros económicos ante las autorizaciones repetitivas del retiro de fondos de pensiones),incremento de la deuda pública (agudizado por el aumento del gasto y la falta de impuestos a los retiros), aumento de los impuestos (ante la necesidad de compensar el gasto público), desincentivo a la compra de activos financieros nacionales (por la falta de base sólida de inversionistas locales), aumento de la vulnerabilidad de la economía a eventos exógenos y menor inversión (reducción del nivel de capital de la economía y el crecimiento económico). Asimismo, afectará la demanda por trabajo, el nivel de ingresos y de empleo, lo que, ante un eventual incremento de la tasa de cotización, es probable que bajen los incentivos en participar en el sistema formal de pensiones.

De esta forma, se constata que, los problemas estructurales del SPP nos revelan cada vez cómo resulta imposible la aplicación consecuente de ciertos principios democráticos mínimos, la participación del Estado para cubrir sus deficiencias y el carácter subordinado al capital financiero, aspectos que se agudizan conforme se vienen desenvolviendo el problema de los retiros de aportes, pues, las medidas apuntan a dos caminos inevitables: Subir la edad legal de jubilación o aumentar la tasa de cotización, ambas medidas que, inevitablemente, perjudicarán al afiliado pero que resultan inevitables dentro de la estructura deteriorada del SPP. El problema del SPP, al ser un sistema fomentado, nos señala claramente que su desnaturalización no empieza con el retiro de sus aportes o medidas similares, sino que, este sistema es la manifestación propia de la desnaturalización (o atraso u obstrucción) de la construcción de una seguridad social nacional.

Por otro lado, las consecuencias subjetivas en la conciencia del afiliado tales como el cortoplacismo al momento de no comprender la importancia del ahorro futuro para atender su situación de vulnerabilidad al llegar a la edad de jubilación o la prevalencia de las necesidad inmediatas por las futuras, se encuentran determinadas por las condiciones materiales a las que se expone en un país subdesarrollado, y por lo tanto, son el efecto inevitable de este; lo que en la estructura del SPP se ve reforzado y difundido. Expuesto así el problema subjetivo, se entiende por qué el problema estructural del SPP no pasa (como ellas suponen), absolutamente, por medidas propagandísticas para resolverlas (v.g. educación financiera del afiliado o que conozca dónde se invierte sus fondos) sino por la transformación de las estructuras económicas donde se erigen como 
instituciones sociales que las condicionan y subordinan en cuanto a la forma que desenvuelven sus políticas previsionales.

Las AFP, al implementarse, expandirse y consolidarse como sistema contradictorio y parasitario al SNP, ha generado un conflicto entre los sectores de afiliados al SPP y SNP, donde, lo primeros, influyen en su concepción individualista y atómica de la protección social en detrimento de los mecanismos (casi destruidos) que deberían ser el horizonte de la población en general. Esta influencia ideológica crea en la sociedad un producto específico de las AFP: El afiliado individualista y cortoplacista, fortaleciendo su figura hasta hacerla hegemónica. Así, se consolida una garantía individual en la posición del afiliado, quien evita o se mantiene al margen de la construcción de una seguridad social y del papel de los fondos invertidos en actividades productivas en nuestro país: Construcción de carreteras, centrales eléctricas, redes eléctricas y de internet, vivienda y toda la infraestructura que todo ello requiere.

Los efectos a largo plazo producto de las contradicciones provenientes de los retiros de los fondos de pensiones apuntan hacia la dirección de mantener intacto y reforzar el SPP, convirtiendo los aportes en el CIC en ahorros individuales forzosos con fines diversos y brindando mecanismos de solución- por parte de las AFP- que implican sobreextraer mayores cuotas de remuneraciones vía aportes (aumento de la edad de jubilación o de la tasa de cotización), lo que refleja el individualismo en las soluciones, caracterizada por estar desarticulada de una política previsional nacional y sólo incidir en la estructura técnica. Estas medidas no se detienen en las cargas individuales, sino que ahonda las diferencias intra e intergeneracional, como la diferencia abismal de los beneficios otorgados entre los afiliados a un SPP o el acceso de los afiliados a las prestaciones de salud sin que aportaran de forma regular. Desde esta perspectiva, el conflicto en la estructura de las AFP no se resuelve dentro de la relación dueños de las AFP- afiliados, sino que se agudiza sin una posible solución más que la de atomizar a los afiliados y alejarlos de los cambios que operen en la estructura económica en la que se asienta el sistema de seguridad social en pensiones.

En los países del Tercer mundo, al haberse agudizado el conflicto por la descentralización productiva, la división internacional del trabajo, la desvalorización de la fuerza de trabajo y el incremento del ejército industrial de reserva, se deja intacto y fortalece la evasión y elusión del pago de cotizaciones, donde el trabajador afiliado al SPP, se desentiende del proceso de vigilancia, participación y fiscalización no sólo por las condiciones materiales subdesarrolladas de existencia sino porque el diseño de las AFP los alejan de dicha actividad, y aún de poder hacerlo, se deforman dichos mecanismos o cargan únicamente al trabajador con los costos de dichos mecanismos. El Estado se presenta como una salvaguarda para atender dichas "fallas" a través de programas no contributivos o sociales, creando, artificialmente, su propio "sistema multipilar”, el cual, no vendría a ser más que, un mecanismo para mantener la sobrevivencia de las AFP y la única forma de que este se mantenga intacto en países de tercer mundo como el nuestro. Así, la política previsional es deformada y entra en contradicción con cualquier proyecto de seguridad social que busque atender el desempleo, falta de vivienda, carencia de alimentación, etc.; por el contrario, la política previsional sólo atenúa los conflictos estructurales de las AFP y destina recursos públicos para atenderlos. 


\section{Conclusiones}

El tipo de seguridad social implementada y fomentada, a través del SPP, por los organismos internacionales se enmarca dentro del contexto de reestructuración del Estado y el sistema económico, cuyos inicios fue a costa del SNP, para posteriormente, expandirse y consolidarse y constituirse en grupos de poder económico. Los dueños de las AFP orientan los fondos de pensiones hacia actividades improductivas y especulativas desarticuladas del desarrollo económico nacional.

Además, el papel de los fondos de pensiones administradas por las AFP han cumplido dos funciones fundamentales: i) A nivel nacional, representan fuentes de ingresos permanentes para los grupos de poder económicos (grupo Romero, Grupo Brescia y Carlos Rodríguez- Pastor) que fueron constituyéndose y consolidándose, a través de sus actividades económicas (principalmente, bancarias), hasta la actualidad; y ii) A nivel internacional, han servido para el financiamiento de actividades especulativas financieras, sobre el que recae la forma principal de inversión que se ha mantenido de forma ininterrumpida. De ello se deriva el papel hegemónico del capital financiero internacional en la forma en cómo se invierten los fondos de pensiones, así como también, el papel del Estado peruano en erigirse como garante económico, estabilizador e impulsor de las AFP; aspectos han sido constatados más aún en la pandemia.

La inexistencia o existencia precaria de la protección social agudizadas por la implementación, expansión y consolidación de las AFP, se manifiestan con mayor crudeza en periodos de la pandemia y particularmente en el problema estructural de los retiros de los fondos de pensiones, donde los afiliados del SPP hacen prevalecer sus necesidades inmediatas ante la obtención de una pensión a futuro (la que tampoco está garantizada) por la creciente volatilidad y devaluación de sus fondos de pensiones, la situación precaria de su existencia, la necesidad de liquidez y la inseguridad del sistema financiero. En tal contexto, las AFP se muestran antagónicas ante las necesidades de los afiliados y hacen prevalecer sus intereses, además, a través del Estado (y sus instituciones) buscan atenuar los efectos de los retiros de los fondos de pensiones; panorama en el que las inversiones en el exterior quedan intactas y se refuerza y fomenta la figura del afiliados individualista y cortoplacista. Los efectos a largo plazo advierten que el grupo etario de 30 a 50 años obtendrá dificultades para acumular fondos suficientes para obtener una pensión adecuada y se enfrentan a un riesgo elevado de caer en situación de pobreza en la etapa de vejez y perder el acceso a prestaciones de salud, situación que se agudizará ante las propias medidas propuestas por las AFP (v.g. aumento de la tasa de cotización o de la edad de jubilación).

Conforme a dichos planteamiento, constatamos que, el papel del SPP en relación con la construcción de una seguridad social, se encuentra caracterizada por: i) No se adscriben como parte de un proyecto u objetivos nacionales vinculados a la industrialización del país, ii) No se vincula al fortalecimiento del capital productivo nacional ni de los sectores económicos estratégicos para el desarrollo económico. Ambos aspectos reflejan una política económica del subdesarrollo en los países de la periferia; asimismo, todo ello ha generado en el SPP lo siguiente: a) que el problema de otorgamiento de pensiones adecuadas, oportunas, suficientes y completas sea un tema subsidiario a tratar, b) imposibilidad de participación democrática de los afiliados (activos e inactivos) y pensionistas, en la toma de decisiones sobre la política previsional, c) falta de financiamiento colectivo, d) Inviabilidad del SPP para ser parte integrante de un sistema de seguridad social nacional vinculado a la redistribución de la riqueza social y a 
la protección de diversos riesgos sociales como: Desempleo, falta de vivienda, subempleo, informalidad, carencia de alimentación, etc.. Se constata así, cómo resulta irreconciliable la forma privada de administrar los fondos de pensiones con las prestaciones sociales otorgadas a los afiliados (activos e inactivos) y pensionistas, lo que resulta un obstáculo para la construcción de una seguridad social genuina.

Por ello, las AFP, ante la posibilidad de construir una seguridad social nacional, adoptan un carácter desintegrador, porque insufla una visión cortoplacista, sin objetivos nacionales y sin perspectiva futura; inmediatista, porque se desenvuelve en función de la coyuntural y ante los cuestionamiento viral de los afiliados, orientando las posibles soluciones a una mera incidencia técnica; subordinada, ya que, los dueños de las AFP son verdaderos intermediarios del capital financiero internacional, financiando sus actividades bancarias e invirtiendo en áreas especulativas vinculadas a proyectos en el exterior; instrumentalizador, porque el Estado se convierte en un instrumento empleado para expandir su dominación, a través de su aquiescencia o accionar, garantizando la estabilidad social ante los conflictos sociales que impliquen cuestionamientos a sus intereses (v.g. vía MEF) y su protección económica (v.g. bonos de reconocimiento) ante la incapacidad para atender el impacto de las crisis económicas y políticas; y parasitario, porque surge como sistema contradictorio al SNP, emergiendo de las entrañas del SNP a través de traspasos de afiliados o su fomento, recurriendo, incluso, al SNP para atender a ciertos sectores de afiliados perjudicados que no consigan una pensión mínima.

La construcción de un sistema de seguridad social real comprenderá objetivos nacionales y la construcción de un Estado- Nación, privilegiando actividades productivas y el desarrollo económico nacional a través de la inversión de los fondos de pensiones en construcción de carreteras, centrales eléctricas, redes eléctricas y de internet, vivienda, etc., y toda la infraestructura que todo ello requiere como parte de transformaciones estructurales al servicio de la industrialización del país.

\section{Bibliografía}

Acuña, Rodrigo; Margozzini, Francisco; Tabilo, Manuel y Vidal, Rodrigo (2021) Retiro de fondos: Desnaturalizando los Sistemas de Pensiones. Una mirada a los efectos de esta política pública. Disponible en: http://www.fiapinternacional.org/wpcontent/uploads/2021/01/Retiro_de_Fondos_Desnaturalizando_los_sistemas_de_pensio nes_FIAP_Ene_2021.pdf (Accedido: 1-3-2021)

AFP Integra (2021) Memoria Anual 2020. Disponible en: https://www.smv.gob.pe/ConsultasP8/temp/MEMORIA\%20AFP\%20INTEGRA\%2020 20_.pdf (Accedido: 17-3-2021)

AFP Habitat (2020) Memoria Anual 2019. Chile. Disponible en: http://www.cmfchile.cl/sitio/aplic/serdoc/ver_sgd.php?s567=48e16b1b3d6c76df2bcde6 e08694660cVFdwQmVVMUVRVEJOUkVFelQxUkpkMDFuUFQwPQ==\&secuencia =1 (Accedido: 1-2-2021)

AFP Habitat (2021) Memoria Anual 2020 de AFP Habitat. Perú. Disponible en: https://www.smv.gob.pe/Frm_Memorias?data=520FE826006982B0E5EA28C44836DF D5D328C975B7 (Accedido: 1-2-2021) 
Banco Central de Reserva del Perú (2020a) Las operaciones repo del BCRP a las AFP no son créditos y protegen los fondos de los afiliados. Disponible en: https://www.bcrp.gob.pe/docs/Transparencia/Notas-Informativas/2020/notainformativa-2020-06-01.pdf (Accedido: 22-1-2021)

Banco Central de Reserva del Perú (2020b) Reporte de estabilidad financiera. Recuperado el 15 de enero del 2021 de: https://www.bcrp.gob.pe/docs/Publicaciones/Reporte-EstabilidadFinanciera/2020/noviembre/ref-noviembre-2020.pdf (Accedido: 15-1-2021)

Bosch, Mariano, Caballero, Gustavo y Keller, Lukas (2020) La libertad de elección en los sistemas de pensiones de ahorro individual: Lecciones de Perú. Disponible en: https://publications.iadb.org/publications/spanish/document/La-libertad-de-eleccion-enlos-sistemas-de-pensiones-de-ahorro-individual-Lecciones-de-Peru.pdf (Accedido: 3-32021)

Comisión de Economía, Banca, Finanzas e Inteligencia Financiera (2020), Dictamen recaído en el proyecto de Ley $N^{\circ}$ 04856/2020-CR, 04954/2020-CR, 04992/2020-CR, 05244/2020-CR, 05323/2020-CR, 05376/2020-CR, 06066/2020-CR, 06093/2020-CR, 06172/2020-CR, 06175/2020-CR, 06214/2020-CR y 06231/2020-CR, Ley que faculta el retiro de los fondos privados de pensiones en el contexto de la pandemia Covid-19. Disponible en: https://leyes.congreso.gob.pe/Documentos/2016_2021/Dictamenes/Proyectos_de_Ley/0 4856DC09MAY-20201022.pdf. (Accedido: 10-1-2021)

Congreso de la República (s.f.1) Exposición de motivos del Decreto de Urgencia $N^{\circ} \quad$ 034-2020. Disponible en: http://spij.minjus.gob.pe/Graficos/Peru/2020/Abril/01/EXP-DU-034-2020.pdf (Accedido: 14-3-2021)

Congreso de la República (s.f.2) Exposición de motivos del Decreto de Urgencia $N^{\circ} \quad$ 038-2020. Disponible en: http://spij.minjus.gob.pe/Graficos/Peru/2020/Abril/14/EXP-DU-038-2020.pdf (Accedido: 14-3-2021)

Congreso de la República (2020a) Expediente Virtual de la ley que establece medidas para aliviar la economía familiar y dinamizar la economía nacional en el año $2020 \quad$ o Ley $N^{\circ} \quad 31017 . \quad$ Disponible en: http://www2.congreso.gob.pe/sicr/tradocestproc/Expvirt_2011.nsf/visbusqptramdoc162 1/04982?opendocument (Accedido: 10-1-2021)

Congreso de la República (2020b) Sesión del Pleno de la primera legislatura para completar el periodo parlamentario 2016- 2021, periodo parlamentario 2016- 2021 (marzo 2020- julio 2020), en Diario de los Debates, 3ra. sesión, vespertina. Disponible en: $\quad$ http://www.congreso.gob.pe/Docs/DGP/diariodebates/files/plo-2020-3.pdf (Accedido: 27-2-2021)

Durand, Francisco (2020) Dueños del País. Disponible n: https://www.facebook.com/permalink.php?story_fbid=10157678131576312\&id=26527 9311311 (Accedido: 20-3-2021) 
Montoro, Carlos (1999): «Costo de la reforma del Sistema Nacional de Pensiones: Una adaptación del modelo de generaciones traslapadas», Revista Estudios Económicos, 4, 57-78.

Oré Chávez, Iván (2007) «El Sistema Privado de Pensiones (Libre Mercado o mercantilismo neocolonial)», en Actas del VII Congreso de Derecho del Trabajo y de la Seguridad Social. Lima- Perú: Editorial San Marcos, 474- 496.

Prima AFP (2020) Memoria Anual 2019. Disponible en: https://www.smv.gob.pe/ConsultasP8/temp/Memoria\%20Anual\%202019.pdf (Accedido: 1-3-2021)

Profuturo AFP (2020) Memoria Anual 2019. Disponible en: https://www.smv.gob.pe/ConsultasP8/temp/Memoria\%20Profuturo\%202019.pdf (Accedido: 1-3-2021)

Rendón Vásquez, Jorge (1993) Sistema Nacional de Pensiones del IPSS o AFP Administradoras de fondos Privados de Pensiones, Guía para adoptar una decisión. Lima: Editor Jurídica Grijley E.I.R.L.

Rendón Vásquez, Jorge (2008) Derecho de la Seguridad Social, 4ta ed., Lima: Editor Jurídica Grijley E.I.R.L.

Rojas, Jorge (2014) El sistema Privado de Pensiones en el Perú. Lima: Fondo Editorial PUCP.

Sindicato Único de Inspectores de Trabajo de la SUNAFIL (2020), Inspectores de trabajo deberán revisar al menos 15,000 casos laborales. Disponible en: https://suitsunafil.org.pe/inspectores-de-trabajo-deberan-revisar-al-menos-15000-casoslaborales/ (Accedido: 14-3-2021) 